THE 'NEW FRONTIER': EMERGENT INDIGENOUS IDENTITIES

AND SOCIAL MEDIA

\title{
Bronwyn Carlson
}

The rapid rise in the use of social media as a means of cultural and social interaction among Aboriginal people and groups is an intriguing development. It is a phenomenon that has not yet gained traction in academia, although interest is gaining momentum as it becomes apparent that the use of social media is becoming an everyday, typical activity. In one episode of Living Black (an Australian television show featuring stories of interest to Indigenous people) entitled “Cyber Wars" (April 19 $9^{\text {th }}, 2010$ ), several Aboriginal people commented on their Facebook use. Allan Clarke, one of the Aboriginal Facebook users featured, stated that, "It's an intrinsic part of our daily routine...." My recently completed doctoral research ${ }^{1}$ reveals that Aboriginal people are active participants on social media sites and in particular on Facebook. In the course of my study, I conducted a content analysis of open Facebook pages that are popular with Aboriginal users, and being an avid Facebook user myself, I was able to navigate through many open pages and explore the activities taking place. In terms of self-representation, the findings from my research reveal that Facebook is becoming a popular vehicle amongst Aboriginal people, to build, display, and perform Aboriginal identities (Lumby 2010). Many Aboriginal Facebook users treat this site as a key self-representational tool to communicate their Aboriginal identity to

${ }^{1}$ Carlson, B. 2011, 'The politics of identity: who counts as Aboriginal today?, Unpublished Doctoral Thesis, University of New South Wales, <http://handle.unsw.edu.au/1959.4/51509> 
other social media users in online communities (generally other Aboriginal people or Aboriginal groups).

In this chapter I will explore the complexities of identifying as Aboriginal at this particular juncture in Australia. I will weave between offline and online spaces, as it seems to me that these are not mutually exclusive. Aboriginal interaction online often mirrors or adheres to offline expectations and regulations -Aboriginal people do not stop being Aboriginal because they are online. In his study of Inuit identities online, Christensen found that the Inuit "are generally embedding offline life into cyberspace" and that "[t]he Internet is not necessarily a space to hide in, nor is it a space that mysteriously filters away the cultural identity of people" $(2003,23)$. I hope to contribute to the discussion about how some Aboriginal people engage with social media and I wish to demonstrate that Aboriginal use of social media is not a peculiarity but rather an everyday activity for many. Social media as a 'new frontier' is where Aboriginal people, like many others, are busy seeking new ways of representing and identifying ourselves to each other-and others-in a global amphitheater.

There is a significant amount of research that suggests that being online provides a disembodied space where subjects can shift and change, and be creative in terms of the identity they choose to display (Robins 2000, Bell and Kennedy 2000, McCormick and Leonard 2007). However, from my research and interactions on social media sites, it seems to me that Aboriginal people embody rather than disembody their identity and cultural engagements when interacting online on social media sites. Christensen (2003) also found this to be the case in his study of Inuits' use of websites. Online identities are the product of cultural practices by real social agents that, while not inhabiting the same spatio-temporal domain, are still very much subject to the same scrutiny and regulations as face-to-face 
interactions. And, in many instances, it is the case that Facebook communication translates into the domain of subjectivity outside of online contexts. For example, 'friends' on Facebook invite others to attend events. Also, many Aboriginal users post pictures of themselves and others attending events to demonstrate their involvement with specific activities. Facebook, unlike many other social networking sites, straddles both the online world and the everyday offline world, where in many cases 'friends' on Facebook are often friends or acquaintances offline (Cooper and Dzara 2010).

Mathew Gardiner Birnbaun's doctoral research found that initial impressions about identity are formed in seconds after viewing a profile and that Facebook profiles helped to form opinions about users and who they are offline $(2008,170-171)$. This is not to suggest that Aboriginal people do not engage in embellishment or creativity in the way they fashion their online profiles. I am sure that many do. Facebook provides an environment where personal identity can be tested and accepted and where connection between the individual (Aboriginal) identity and the collective (Aboriginal) identity can develop. My research has identified cases where Aboriginal Facebook users feel the need to overly 'Aboriginalise' their profile page so other Aboriginal people will 'see' them as Aboriginal, and instances where anxiety is expressed when profiles do not demonstrate Aboriginality at first glance (Lumby 2010). Facebook allows the potential for creative interaction that can be more challenging to maintain in offline communications. As I will demonstrate, this is not to suggest that questioning and accusations do not penetrate the site, or that the threat of 'real' bodies does not occur (Fraser and Dutta 2008). I am sure many Aboriginal people are using social media and social networking sites such as Facebook in a variety of ways that are not always about being identified as Aboriginal. However, I am interested in the circumstances where Aboriginal people want to be identified, or 
are openly expressing or displaying Aboriginality online. To be Aboriginal online then, requires recognition from other people, and specifically other Aboriginal people, much in the same way that offline identities demand recognition.

Online Aboriginal identities assume a level of performativity in the sense that Judith Butler applies this term: “...that reiterative power of discourse to produce the phenomena that it regulates and constrains" (Butler 1993, 2). Like other modes of subjectivity, online identity for Aboriginal subjects acquires reality through the surveillance that, in Butler's words, regulates and constrains it. My research shows that in relation to identity creation, it is not just a matter of 'being' Aboriginal in an online site, but rather, Aboriginality must be 'done'. In other words, the performance of Aboriginality is necessary for the subject position to be taken seriously, and for recognition to occur in a meaningful way or a way that is likely to inscribe the subject's cultural identity as publicly recognised and affirmed. Indeed, the performative dimension of online identity for Aboriginal people is crucial. Performativity is an ongoing act of the 'casting' of self that requires "cultural capital" and access to the constitutive discursive elements of Aboriginality in order for recognition to be effective (Papacharissi 2011). These include, but are not limited to: knowledge of particular types of language, membership in organisations, participation in certain causes, the sending and receipt of recognisable Indigenous iconography, imagery, the posting of political statements, and the knowledge of particular community organisations, structures and practices. Political causes can include issues found on Facebook such as, "Stop the NT intervention", "Indigenous health inequality in 25 years", "Say stop to racism", and "Stolen Generation-Bringing them back home". In addition, users can add images, such as Aboriginal flags and icons demonstrating affiliation. Iconography is attached to a 
profile under headings such as "Koori Pride" and "Nunga Pride"2. An icon can be sent as a 'gift' to a 'friend' that declares or confirms identity, or denotes a particular affiliation with an interest group. The receipt of such a 'gift' can constitute the giver's acknowledgment of a user's Aboriginality. Music is another way to demonstrate Aboriginal identity. For example, links to the currently popular profile page of acclaimed Aboriginal musicians, Geoffrey Gurrumul Yunupingu and Archie Roach testify to an interest in Aboriginal music and musicians. When a user joins a network, the network is displayed on their page, and their profile is displayed on the network page. So if a user joined Archie Roach's page, their profile would be displayed on that page. Anyone visiting the page would see who were members or 'friends'. The more 'friends' and networks one adds or joins, the bigger and more visible the profile. My study revealed that 'doing' Aboriginality on Facebook requires ongoing attention and effort to maintain public recognition and to ensure the endorsement of Aboriginal status. 'Doing' Aboriginality is a work-in-progress for many, as "the curtain never comes down on the ritual of identity fabrication and selfexhibition" (Fraser and Dutta 2008, 40). It can be time-consuming and with the capacity to attract both acknowledgement and repudiation; "Rewards for fame and punishments for shame are sometimes distributed in unexpected ways... 'know thyself becomes 'show thyself" (ibid.).

In contemporary Australia, Aboriginal identity is not a straightforward affair. There is much debate circulating in both academic and community spaces (both online and offline) about who counts or should count as Aboriginal and, who could or should

\footnotetext{
2 'Koori' and 'Nunga' are terms used by Aboriginal people to refer to themselves and have geographical relevance. 'Koori' refers to Aboriginal people from New South Wales and Victoria and 'Nunga' refers to Aboriginal people from South Australia.
} 
confirm such claims (Noble, 1996; Oxenham et al. 1999; Huggins, 2003; Paradies, 2006; Lamb, 2007; Heiss, 2007; Bond, 2007; Ganter, 2008; Gorringe et al. 2011; Carlson 2011). The following two examples illustrate the current concerns by some Aboriginal people about who counts as Aboriginal. The Australian Institute of Aboriginal and Torres Strait Islander Studies (AIATSIS) facilitated two workshops one in 2009 and one in 2011. The outcomes from both workshops contributed to the 2011 publication titled, 'Will the real Aborigines please stand up: Strategies for breaking stereotypes and changing the conversation' (Gorringe et al. 2011). The workshops sought the input of Aboriginal people, in various locations, answering the question of who or what should count as Aboriginal. Similarly, the NSW Aboriginal Education Consultative Group (AECG), after becoming "increasingly concerned about the increased level of community concern regarding issues of Aboriginal identity" $(2011,9)$, published their report based on community consultations in 2011, titled, 'Aboriginality and Identity: Perspectives, Practices and Policies'. The report states that, "[T]he issue of Aboriginality and identity is one of the most critical issues in contemporary Aboriginal affairs..." and notes the "growing community concern and uncertainty about who is and who is not Aboriginal and how Aboriginality is defined and determined..." (AECG 2011, 5). In its report, the AECG recommended that the current definition of Aboriginality, as defined by the NSW Aboriginal Land Rights Act (1983), be supported. The Act states that, "An Aboriginal person means a person who: a) is a member of the Aboriginal Race of Australia, and b) identifies as an Aboriginal person, and c) is accepted by the Aboriginal community as an Aboriginal person" (ibid.).

This three-part assessment was introduced by the government in the late 1970s as a means to identify Aboriginal people for the purposes of administering resources and funding. However, it is quickly becoming 
a process that Aboriginal people require of each other to confirm their Aboriginal status. Proof of the last condition requires a supporting letter from an Aboriginal council or organisation. Formal Confirmation of Aboriginality is important to have in order to apply for scholarships, to work in identified positions, and to access services designed specifically for Aboriginal people. It is not a trivial or sentimental document; it is a quasi-legal document, which can be and is used to evidence claims of Aboriginality. The three-pronged definition however, does not always fit the multitude of experiences, relocations and policy prescriptions that Aboriginal people have had to face under colonial conditions (Carlson 2011). While most who seek a formal Confirmation of Aboriginality document already identify and, know or have traced their family lineages, the issue of being recognised and accepted 'by the community in which he/she lives' can provide a stumbling block given the diasporas position of many Aboriginal people. It should also be noted that possessing a Confirmation of Aboriginality document does not always shield the possessor from accusations of not being Aboriginal. Nobody is exempt from being questioned, as Anita Heiss explains: "[i]n our own Aboriginal community, comments in discussions around who is and who is not Aboriginal can range from "They're not black enough" to accusing individuals of being "Johnny-come-lately's" (2007, 51). Heiss also notes that "[c]riticism of Aboriginal people by Aboriginal people is strong, and no one escapes" $(2007,53)$.

Given that the Aboriginal community is tasked with confirming claims of Aboriginality, one would assume that there is a consensus on what constitutes 'the community'. However, this is not the case. The notion of Aboriginal community is complex. Peters-Little suggests that government policies and community organisations have been largely "shaping 'who' and 'what' constitutes an Aboriginal community" (2001, 198). While throughout colonial history new 
Aboriginal communities emerged through enforced relocation and dislocation from ancestral country, the axiom the Aboriginal community' has only become entrenched in popular discourse since the 1970s to streamline government funding to Aboriginal people. Since the introduction of the term "community" into the public lexicon, Aboriginal organisations have taken charge of the meaning of the term, particularly in urban settings where it has specific connotations of official 'authority' at local levels (see Yamanouchi 2007, 2010). Furthermore, 'community participation' is recognised by participation in events hosted by Aboriginal organisations and by attendance at meetings (Yamanouchi 2007, 140). Conversely, "[i]t is within organisations' activities and events that people have their strongest sense of being part of an experience they call community" (2007, 144). Yuriko Yamanouchi's participants from southwest Sydney also reported that Aboriginal people who do not participate in organisations' activities "do not have much to do with the community" (ibid.). The inference is that community organisations are community.

Many questions emerge at these discursive boundaries as to what constitutes 'community', and therefore who can speak for, or confirm, an individual's identity (Lamb 2007). In the recent Weekend Australian Magazine (March 24-25, 2012), an article titled "Not so Black and White" details Aboriginal man Dallas Scott's experience of applying for a Confirmation of Aboriginality certificate, and his subsequent denial of one (Overington 2012, 15). Scott states that he has identified himself as Aboriginal all his life but when he wanted to access a service specifically designated for Aboriginal people, he was asked to provide proof of his identity. Scott was shocked by the rejection of his application for a Confirmation of Aboriginality document claiming, "Every time I walk out the door I'm Aboriginal, and suddenly I'm not" $(2012,15)$. Scott then logged into Facebook 
and updated his status, "Dallas Scott...is apparently not Aboriginal after all" (ibid.). Scott turned to the online community to air his discontent and this led to further discussion with his online 'friends' about his status as Aboriginal. Scott's actions lead me to wonder if he felt that he was part of an online community: a place where everyday issues can be blogged about, where opinions can be expressed and support rallied. I also wondered if Facebook provided Scott with an online community where his Aboriginal identity was acceptedperhaps without question.

Many questions arise where answers evade me. Do online social networking sites reinforce and intensify current conceptualisations of Aboriginal identity or community? Or, is it that online spaces fracture old and broker new forms, or do new forms solidify around more varied and dispersed sets of shared interests? What of the continuum or connection between online and offline activity? What happens if an Aboriginal identity is rejected offline yet accepted online-do one's 'friends' become the locus to confirm and authenticate Aboriginality? Can social networking sites have the potential to act as verifiers of Aboriginal identity, or is that too 'out there' for us to consider? Facebook is arguably an example of an online community and is described by Acquisti and Gross $(2006,38)$ as an "internet community where individuals interact, often through profiles that (re)present their public persona (and their networks of connections) to others". On Facebook, members create their own profile page, and links to other profiles by joining groups, adding friends or 'liking' other pages (such as movies, music, political causes etc.). The pages that a user 'likes' are then displayed for others to view or post comments about. Users have the ability to post status updates to let 'friends' know what they are thinking or feeling at any given time just as Scott did in the above example. The ultimate purpose of having a Facebook page is 
that others will view a user's page, 'like' what they like and interact by commenting on activity.

Facebook 'friends' may be known in offline contexts, or are people connected online through known or unknown networks. Most Facebook users tend to 'friend' others who are similar in terms of identity, interests and networks. According to Di Micco and Millen's (2007) study of "multiple presentations of self in Facebook", most users were aware of how they represented themselves and did so with the intention of establishing a particular view of themselves. The study found that users represented themselves to fit with specific networks or communities $(2007,383)$. Facebook, though a communication tool, also functions to create and (re)present to others a public identity, and to attract similar profiles as part of a broader network or community (Lumby 2010). The core functionality of Facebook is that users have the ability to connect with others ('friends') and form or belong to groups that are similar or have similar interests, just as one would do offline. The idea is to increase one's 'friends' list, which then acts as corroborating evidence of a user's networks. If authenticating Aboriginality requires community recognition, does the online community count in this endorsement? If so, then the Facebook function of 'friends' would play a critical role in this endorsement of status and therefore the number of 'friends' listed would be just as important as the profile of the 'friends'. That is, one would need Aboriginal 'friends'.

I was afforded an opportunity to test the proposition that online communities such as Facebook may have, now or in the future, some role in authenticating or recognising claims of Aboriginality. At a recent conference where I presented research on social networking sites, an Aboriginal woman asked if I would join a Facebook site dedicated to Aboriginal and Torres Strait Islander scholars. The site is 
ostensibly for selected Indigenous people to discuss Indigenous topics of interest. Membership demanded confirmation of my Aboriginality by two existing members. I was accepted and was asked to pose a question for the group to encourage discussion. In line with my research interests, I posted, "Can community recognition of someone's Aboriginality come from an online community?" One respondent stated, "Community Recognition is just that!!!" implying that there is only one form of 'community'-and that is offline. I responded that my question had emerged in the course of my research and was not a personal assertion but intended as an idea for consideration and discussion. Responses immediately shifted from my posed question to vitriolic demands for my authentication-in particular for documented evidence of my Aboriginality. I responded that I did have a Confirmation of Aboriginality. I was then asked for further corroboration: was I a member of an Aboriginal Lands Council? I replied affirmatively. Another respondent claimed I was "NOT Aboriginal" and made mention of knowing my workplace and where they could find me. Finally, I was informed I would be removed from the group as my identity was under question. The response was followed by, "[A]nd for the record community recognition in cyberspace please, nothing can replace the real thing". This experience solidified for me that there is indeed a continuum between offline and online activity in terms of identity recognition or indeed, the refusal of recognition. The boundaries of who or what can count as Aboriginal are guarded well in both online and offline spaces. So, regardless of the assertion that 'the community' existed only in an offline context, my Aboriginality was denounced in this online space and I was reminded that this would have offline ramifications, as it was known where I could be located.

Self-surveillance and the surveillance of others is an everyday part of engaging with Facebook. Indeed, this is but a microcosm of the 
Internet's potential as a modern phenomenon increasingly driven by the desire of users to watch, monitor, scrutinise and emulate. Facebook users can never be certain if they are being monitored or not at any given time. In fact, it is expected that 'friends' will visit user profiles to read thoughts, conversations, likes, dislikes, and evaluate representations of a user's identity. Users typically don't want to betray social or cultural norms so, to some extent, they fashion their profiles so as not to wander from what might be expected (Subramanian 2010). For instance, if a user wanted to ensure that their Aboriginality was known and accepted they would not make statements that conflict with those expressed by the majority of members: to be part of a group often demands complicity to the group's professed belief system. A lesson which I learned myself online. Online surveillance, or "dataveillance", according to Michael Zimmer $(2008,79)$, "Encompasses a diverse range of activities and processes concerned with scrutinizing people, their actions, and the spaces they inhabit”. This calls to mind Foucault's (1995) analysis of Jeremy Bentham's model penitentiary, the Panopticon. Bentham's panopticon prison was designed to function as a round the clock surveillance machine that had the capability to oversee all prison activity at all times. The idea, simply put, was that the prisoner knew of the possibility for continual surveillance and therefore internalised this practice to reproduce a practice of constant self-surveillance. As Foucault states, "surveillance is permanent in its effects, even if it is discontinuous in its actions" (Foucault 1995, 201). On Facebook, one should assume that others might be watching. The censoring of identity takes many forms, but central to surveillance and selfsurveillance is the fear of being publicly dis-authenticated. It is this fear that regulates behaviour.

Despite my experience of expulsion, I am fascinated by the potential that social media may offer Aboriginal people. The rapid advances in 
mobile technologies and the uptake of these by Aboriginal youth in particular, can be seen in many communities (see, Kral 2011). I do not want to suggest there is no digital divide; rather, I want to counter any assumptions that Aboriginal people may have little interest in the possibilities of technology and the online environment. It is also apparent that such use is not limited to Aboriginal people living in urban settings. Kral's $(2011,5)$ research into how Aboriginal youth in remote Australia utilise digital technologies and social media revealed the popularity of Facebook as a platform to "upload their multimedia productions, comment on each others' mobile phone 'pics' and announce the immediacy of their activities with online chat". Interestingly, Kral also reports "they are also using these channels to air their thoughts and the cultural activities and concerns of their community" (2011, 5). Similarly, the recent publication, Our Place: People working with technology in remote communities ${ }^{3}$ (Nadarajah 2011) highlighted the use of Facebook by residents from the remote community Ti Tree in Central Australia. The story features April Campbell, an Anmatyerre woman, who actively uses Facebook not only to keep in contact with friends and relatives, but also to post news and information about her projects. Aboriginal people from all over Australia are connecting with April via Facebook where various language speakers interact and network with her online (2011). The notion of local in terms of community can be seen to be shifting. Now, in the online context, local can mean national or even global.

A friend of mine shared a story with me about his experience with Facebook. My friend managed an Aboriginal health service in a remote community and he had difficulty reaching many of the members of the community to let them know about health promotion

\footnotetext{
${ }^{3}$ Our Place: People working with technology in remote communities, issue number 39, May 2011, available at, http://www.icat.org.au/default.asp?action=article $\& I D=3$
} 
activities. One morning a staff member did not show for work and another mentioned that they had a late night so would probably not come it. My friend asked if the person had telephoned and was told that this information had been deduced from the staff member's Facebook profile. My friend was a little surprised to hear that the staff members, who were aged in their 50s, were Facebook users. When he commented to the staff member that he hadn't realised she was on Facebook, she replied, "We are all on Facebook". He told me that he then established a Facebook page dedicated to the health service and many of the community members 'liked' the page and he was then able to reach a larger number of community members than he had previously been able to.

On a personal note, I am one of four born to my mother who raised me. My father has ten children of which I am one. So, outside my immediate siblings I have six others who I was not raised with. As adults we have all found each other on Facebook. On Facebook, all of our children have come to know each other as well. My uncle, who I have not seen since I was a small child, has also found us on the site. In this online space, temporality and spatiality have been traversed and our family has grown exponentially. The potential for rekindling kinship on Facebook is worthy of further thought particularly in the wake of colonialism that has seen many Aboriginal families torn apart. One result is that some Aboriginal people have limited or no knowledge of where they would or should be connected genealogically. Facebook offers mechanisms that map and record place in ways that prior technologies have not. It places the user within a matrix of social connections that act as documented evidence to claims of kinship, country and local recognition. This element of Facebook has enormous consequences for Aboriginal people for whom, prior to this technology, identity was a matter of continual anxiety as there was often no public reference point for 
authentication. Facebook, while also presenting its own regulating force, has the potential for recognition as a valid online public record of self-assessment, self-representation and self-validation. Facebook is a site where connections with Aboriginal people function not merely as an artifice of online technology, but as real, lived stories that are recorded and shared and that can act as written testimonials to personal histories.

Though here I highlight Aboriginal people's active engagement with social media, I am aware that a contradictory argument can be made. The use of social media may well lead to many changes or different ways of understanding social and cultural interactions and maybe even to the way Aboriginal communities are conceptualised. Aboriginal people are diverse and have different opinions and experiences. It is therefore the case that there is no universal consensus on the issue of identity and culture in relation to social media. There are those who will assert that modern technology does not 'fit' with what they see as cultural practice. This view of course tends to deny Aboriginal people's use of technology, imposed and otherwise, for millennia. There are also those who guard the offline community boundaries and feel less able to identify the boundaries online; fear of the unknown terrain could induce rejection of the possibility for an online Aboriginal community and would reject the notion that the online community could or should count especially in terms of recognising Aboriginality. There are many who have only recently found out that they are of Aboriginal heritage. Given Australia's colonial history, this is not uncommon. Will Facebook and online communities offer the newly identifying a safe place to test the water?

My doctoral research indicated that Facebook might provide an avenue where newly identifying Aboriginal people can interact and 
join Aboriginal groups and develop confidence in claiming their identity both in online and offline spaces. On Facebook, users can grow networks, add Aboriginal 'friends' and learn from others. I am not suggesting that Facebook would offer safety from scrutinyclearly my own example illustrates surveillance is practiced onlinebut Facebook does provide a certain distance where one can have time to respond (which is often not afforded in face-to-face interactions). As Christopher Pullen suggests of social media, "The potential to connect to diverse individuals in the formation of community offers both the affirmation of identity and opportunities to test out concepts or imaginations of self" $(2010,7)$. Facebook provides a platform for the exploration of Aboriginal identity, the observation of others' Aboriginality, and the discursive act of re-presenting identity where this is ambiguous, fraught or unknown. It is here in the online space that subjects can consciously shape themselves to meet the expectations of other Aboriginal people who may be looking. As evidenced in the Manago et al study, users of social networking sites "construct a sense of self in relation to what their peers are doing, gauging their progression in comparison to others" $(2008,452)$. This study reports that users spend time observing other people's profiles comparing themselves with "idealized images" (2008, p. 452). This self-surveillance technique means that "[p]ossible selves may be transformed into actual selves" $(2008,454)$ particularly if public approval is accorded. My research on this topic suggests a rich site for future inquiry around the meanings, construction, negotiation, expressions and confirmation of Aboriginal identity in Australia. It is interesting to consider what Aboriginal activity in the online environment means for the future notion of the 'Aboriginal community' and if the online community has any capacity to be recognised as an authenticating body for the recognition of Aboriginality. Will we reach a point in the future where we will hear Aboriginal people's claim to Aboriginality being declined because they 
are not known on Facebook? Or indeed, will we reach a point where authentication can become an online set of practices, administered and authorised by Aboriginal people?

Earlier this year an article appeared in the Herald Sun, with the headline, 'Indigenous leaders want to ban or censor social media including Facebook'4. In this case some Aboriginal people living in a remote location were calling for a ban on Facebook and social networking, as it was believed that it was fueling community tensions and what is referred to as "old family rivalry and blood feuds". In this community, what took place on Facebook also took place offline. It is reported that a street brawl occurred after exchanges on social media sites reignited a long-standing feud. So while some in this community were calling for a ban of social media, others were against censorship and were calling for more education in order that the community could have a better understanding of the capacity of social media ${ }^{5}$. What can be gleaned from Aboriginal use of social media, in my mind, is that Aboriginal social network users do not necessarily take on an online identity that is somehow dislocated or removed from their offline identity. That is, those who identify as Aboriginal offline tend to also identify as Aboriginal online. This seems to point to a divergence from the ways that many non-Aboriginal people use Facebook as a site where identities can be fabricated as a matter of

\footnotetext{
${ }^{4}$ The Herald Sun, 'Indigenous leaders want to ban or censor social media including Facebook', available at, <http://www.heraldsun.com.au/news/morenews/indigenous-leaders-want-to-ban-or-censor-social-media-includingfacebook/story-fn7x8me2-1226237794483>

${ }^{5}$ It should be noted that online/offline community violence is not an Aboriginal issue, but a phenomenon across all communities, as can be seen by the use of social media in riots such as those in London. See a call to block social media in instances of riots, <http://www.smh.com.au/technology/technologynews/london-riot-social-media-blocks-totalitarian-20110812-1iq0o.html>
} 
choice rather than being a cultural affirmation. Aboriginal people, according to my research, actively use social media and are interested in what this might mean for us in terms of our cultural practices. This is borne out by the Australian Institute of Aboriginal and Torres Strait Islander Studies (AIATIS), which hosted a conference entitled 'Information Technologies and Indigenous Communities' on July $13^{\text {th }}-15^{\text {th }} 2010$. Among the topics discussed was 'Facebook and Social Networking. ${ }^{6}$ The session description claimed that sites such as Facebook "are going to be a critical part of life in your community in the future. New technology allows the creation of new linkages that have not been seen in our cultures before" $(2010,30)$. Clearly, the use of social networking is being discussed in scholarly and other contexts among Aboriginal communities and organisations, both offline and online. We still have a lot to learn about Aboriginal use of social media and the potential that social media may offer in terms of social and cultural interaction. But one thing is quite clear-social media is here, Aboriginal people are online and are posting and interacting with one another, having conversations, debates and forming relationships. Social media is a social site but as I have demonstrated, it is also a political site where Aboriginal struggles and identities are being played out in the 'new frontier'.

\section{References}

Aboriginal Education Consultative Group. 'Aboriginality and identity: perspectives, practices and policies.' Produced by Bob

\footnotetext{
${ }^{6}$ Information about The Australian Institute of Aboriginal and Torres Strait Islander Studies conference titled 'Information Technologies and Indigenous Communities' 2010 can be accessed at, $<$ http://www.aiatsis.gov.au/research/symposia/Digi10/theme.html>
} 
Morgan Consultancy, 2011.

http://www.nrsdc.org.au/images/newsletter/Aboriginality_an

d_Identity_Report_November_2011.pdf

Acquisti, A. and R. Gross. 'Imagined communities: awareness, information sharing, and privacy on Facebook.' A paper presented at the Privacy Enhancing Technology workshop, Robinson College, Cambridge, June 28-30, 2006.

Bell, D and B. M. Kennedy, eds. The Cybercultures Reader. London: Routledge, 2000.

Bond, C. 'When you're black, they look at you harder: Narrating Aboriginality within public health', Unpublished Doctoral Thesis, University of Queensland, 2007.

Butler, J. Bodies That Matter: On the Discursive Limits of "Sex". New York: Routledge, 1993.

Carlson, B. 'The politics of identity: who counts as Aboriginal today?' Unpublished Doctoral Thesis, University of New South Wales, 2011.

Christensen, N. Inuit in Cyberspace: Embedding Offline Identities Online. Copenhagen:

Museum Tusculanum Press, 2003.

Cooper, M and K. Dzara. "The Facebook Revolution: LGBT Identity and

Activism." In LGBT Identity and Online New Media, edited by C. Pullen and M. Cooper, 100-112. New York: Routledge, 2010.

DiMicco, J.M. and Millen, D.R. 'Identity Management: Multiple Presentations of Self in Facebook.' Proceedings of the 2007 International Association for Computing Machinery Conference on Supporting Group Work, Florida, November 4-7, 2007: 383-386. 
Foucault, M. Discipline and Punish; The Birth of the Prison. New York: Vintage, 1995.

Fraser, M. and S. Dutta. Throwing Sheep in the Boardroom: How Online Social Networking Will Transform Your Life, Work and World. West Sussex: John Wiley \& Sons, 2008.

Ganter, R. 'Turning Aboriginal - Historical Bents.' Borderlands ejournal 7, no. 2 (2008): 1-19. Accessed May 132010.

http://www.borderlands.net.au/vol7no2_2008/ganter_turning .pdf

Gardner Birnbaum, M. 'Taking Goffman on a Tour of Facebook: College Students and the Presentation of Self in a Mediated Digital Environment.' Unpublished Doctoral Thesis, University of Arizona, 2008.

Gorringe, S., Ross, J. \& Forde, C. 'Will the real Aborigines please stand up': Strategies for breaking the stereotypes and changing the conversation.' Australian Institute of Aboriginal and Torres Strait Islander Studies, Discussion paper 28, 2011.

Heiss, A. 'Writing Aboriginality: Authors on 'Being Aboriginal'.' In A Companion to Australian Literature since 1900, edited by N. Birns and R. McNeer, 41-59. New York: Camden House, 2007.

Huggins, J. 'Always was, always will be.' In Blacklines: Contemporary Critical Writings by Indigenous Australians, edited by M. Grossman, 60-65. Carlton: Melbourne University Press, 2003.

Kral, I. 'Youth Media as Cultural Practice: Remote Indigenous Youth Speaking Out Loud.' Australian Aboriginal Studies 1 (2011): 416.

Lamb, N. 'Aboriginalising Racism - Regional Experiences of Racism Between Aboriginal Groups.' Paper presented at the International Conference on Racism in the New World Order: Realities of Colour, Culture and Identity Conference, University of the Sunshine Coast, Maroochydore, 2007: 177- 
183. http://www.usc.edu.au/nr/rdonlyres/b48e9bb0-04ae4d95-b710-512fd0973954/0/racismsconf3.pdf

Living Black, 'Cyber Wars.' Special Broadcasting Service, April 19, 2010.

Lumby, B. 'Cyber-Indigeneity: Urban Indigenous identity on Facebook.' The Australian Journal of Indigenous Education 39 (2010): 68-75.

Manago, A M., M B. Graham, P. M. Greenfield and G. Salimkhan. 'Selfpresentation and gender on Myspace.' Journal of Applied Development Psychology 29 (2008): 446-458.

McCormick, N. and J. Leonard. 'Gender and Sexuality in the Cyberspace Frontier.' Women and Therapy 19.4 (1996): 109119.

Nadarajah, H. 'Can You Be My Facebook Friend?: Reaching Out Across Language Groups.' Our Place: People Working With Technology in Remote Communities 39 (2011): 6-9.

Noble, F. 'Who Do We Think We Are: People Who Are Learning About their Aboriginality.' Unpublished Masters Thesis, Griffith University, 1996.

Overington, C. "Not so Black and White." Weekend Australian Magazine. March 24-25, 2012.

Oxenham, D, J Cameron, K Collard, P Dudgeon, D Garvey, M Kickett, T Kickett, J Roberts and J Whiteway. A Dialogue on Indigenous identity: Warts ' $n$ ' all. Perth: Gunada Press, 1999.

Paradies, Yin C. 'Beyond Black and White: Essentialism, Hybridity and Indigeneity.'Journal of Sociology 42, no. 4 (2006): 355367.

Papacharissi, Z, ed. A Networked Self: Identity, Community, and Culture on Social Network Sites. New York: New York, 2011.

Peters-Little, F. 'The Community Game: Aboriginal Self Definition at the Local Level.' In The Indigenous Welfare Economy and the CDEP Scheme, Centre for Aboriginal Economic Policy 
Research, edited by Frances Morphy and Will Sanders, 187192. Canberra: ANU EPress, 2001, Accessed May 132010.

Pullen, C. 'Introduction.' In LGBT Identity and Online New Media, edited by Christopher Pullen and Margaret Cooper, 1-16. New York: Routledge, 2010.

Robins, K. 'Cyberspace and the World We Live In.' In The Cybercultures Reader, edited by David Bell and Barbara M. Kennedy, 77-95. London: Routledge, 2000.

Subramanian, M. 'New Modes of Communication: Web Representation and Blogs: United States: South Asians.' Encyclopaedia of Women and Islamic Cultures (2010). http://referenceworks.brillonline.com/entries/encyclopedia-ofwomen-and-islamic-cultures/new-modes-of-communicationweb-representations-and-blogs-united-states-south-asiansCOM_0660

The Australian Institute of Aboriginal and Torres Strait Islander Studies conference titled 'Information Technologies and Indigenous Communities' 2010. Accessed at, http://www.aiatsis.gov.au/research/symposia/Digi10/theme.ht $\mathrm{ml}$

Yamanouchi, Y. 'Searching for Aboriginal Community in South Western Sydney.' Unpublished Doctoral Thesis, University of Sydney, 2007.

Yamanouchi, Y. 'Kinship, Organisations and 'Wannabes': Aboriginal Identity Negotiation in South-western Sydney.' Oceania 80 (2010): 216-228.

Zimmer, M. 'The Gaze of the Perfect Search Engine: Google as an Infrastructure of Dataveillance.' In Web search: Multidisciplinary Perspectives, edited by Zimmer, M. and A. Spink, A, 77-99. Dordrecht: Springer, 2008. 